\title{
Identification and partial characterisation of an extracellular activator of fatty acid modifying enzyme (FAME) expression in Staphylococcus epidermidis
}

\author{
N. R. CHAMBERLAIN \\ Department of Microbiology/Immunology, Kirksville College of Osteopathic Medicine, Kirksville, MO, USA
}

\begin{abstract}
Fatty acid modifying enzyme (FAME) is an extracellular enzyme that inactivates bactericidal fatty acids by esterifying them to cholesterol. Inactivation of these fatty acids may allow Staphylococcus epidermidis to live for long periods of time on the skin. This study describes the identification and partial characterisation of an extracellular activator of FAME production. Addition of FAME-free concentrated culture filtrate (activator) to $S$. epidermidis cultures $\left(\mathrm{OD}_{600}=0.05\right)$ caused a 3-5-fold increase in FAME activity. Addition of the activator did not increase the amount of exopolysaccharide produced by $S$. epidermidis. The mol.wt of this activator was $<3000 \mathrm{kDa}$ and it was quite resistant to boiling. Treatment of the activator with proteinase $K$ did not destroy its ability to induce FAME expression. Addition of $S$. aureus activator to $S$. epidermidis cultures also increased FAME expression. However, when $S$. epidermidis activator was added to $S$. aureus cultures no increase or inhibition in FAME production was observed.
\end{abstract}

\section{Introduction}

Staphylococcus epidermidis is a coagulase-negative staphylococcus that colonises human skin [1]. Hospitalised patients frequently undergo invasive procedures that compromise protection by the skin and allow $S$. epidermidis to grow on foreign bodies that have been inserted into the patient [2].

To colonise such a hostile environment as the skin, $S$. epidermidis has developed several survival mechanisms. The sebaceous glands in the skin secrete factors that are bactericidal to gram-positive bacteria [3-7]; these factors include long-chain fatty acids and monoglycerides. S. epidermidis is highly susceptible to killing by fatty acids [4]. Previous studies have demonstrated the production of an extracellular enzyme called fatty acid modifying enzyme (FAME) by strains of $S$. epidermidis [8,9]. This enzyme can inactivate fatty acid-associated bactericidal activity by

Received 2 April 1998; revised version accepted 11 July 1998.

Corresponding author: Dr N.R. Chamberlain (e-mail: nealc@fileserver4.kcom.edu). esterification to cholesterol $[10,11]$ and may protect $S$. epidermidis from these bactericidal lipids on the skin.

FAME activity is not produced in significant amounts by $S$. epidermidis until early in the stationary phase [9]. Lipase is produced by $S$. epidermidis in a very similar fashion [12]. The ability to delay production of extracellular factors may be beneficial to the organism in colonising the skin.

Regulation of extracellular factors by a two-component global regulator (agr) delays production of extracellular factors by $S$. aureus [13-15]. Other investigators have identified and cloned an agr-like locus from $S$. epidermidis [16]. The agr-like locus of $S$. epidermidis is very similar $(80-90 \%$ DNA homology) to the two-component regulator agr locus in $S$. aureus [16]. If this agr-like locus in $S$. epidermidis controls lipase and FAME production, this could explain why these extracellular enzymes are not produced until early stationary phase.

The agr regulator is turned on in $S$. aureus by a small peptide called an activator that binds to the membrane receptor $[17,18]$. The present studies sought to determine if a similar activator exists in $S$. epidermidis and if activators from $S$. epidermidis and $S$. aureus affect FAME production between the two species. 


\section{Materials and methods}

\section{Bacterial strains}

S. epidermidis strains $37,45,52$ and 54 were described previously [9]. S. aureus DU5720 was described previously [19] and was a generous gift from $\mathrm{Dr}$ T. J. Foster (Dublin, Ireland).

\section{Collection of culture filtrates and FAME assay}

Culture filtrates were obtained by passing the culture through a $0.2-\mu \mathrm{m}$ sterile filter (Acrodisc for volumes $<1 \mathrm{ml}$ and with a VacuCap 90 for larger volumes; Gelman Sciences, USA). The culture filtrates were then divided into small volumes and stored at $4^{\circ} \mathrm{C}$ until needed for assay. Acetone $(5 \mu \mathrm{l})$ containing $\left[7-{ }^{3} \mathrm{H}\right]$ cholesterol (200000 dpms; specific activity = $23.8 \mathrm{Ci} / \mathrm{mmol}$; New England Nuclear, USA) and $2.5 \mu \mathrm{g}$ of oleic acid [9] was added to the culture filtrates ( $100 \mu \mathrm{l}$ for $S$. epidermidis or $5 \mu \mathrm{l}$ for $S$. aureus diluted in $95 \mu \mathrm{l}$ of $20 \mathrm{mM} \mathrm{MES}, 170 \mathrm{mM} \mathrm{NaCl}, \mathrm{pH}$ 6.0). Samples were incubated for $30 \mathrm{~min}$ at $37^{\circ} \mathrm{C}$. The lipids were extracted with $200 \mu \mathrm{l}$ of ethyl ether:methanol (6:1). The lower phase was discarded and the upper organic phase was dried in a stream of nitrogen gas. The dried lipids were then suspended in $100 \mu \mathrm{l}$ of hexane:ethyl ether:glacial acetic acid (73:25:2; $\mathrm{H}: \mathrm{EE}: \mathrm{AA})$. The cholesterol ester was separated from unreacted radiolabelled cholesterol with silica gel columns [9]. Slurries of silica gel (average particle size $40 \mu \mathrm{m}$; VWR Scientific, USA) in H:EE:AA were used to make 0.6-g columns (dry weight; $5.3 \mathrm{~cm} \times 0.5 \mathrm{~cm})$ in $23-\mathrm{cm}$ Pasteur pipettes plugged with siliconised glass wool. The suspended samples were placed on the column and the cholesterol esters were eluted in $2 \mathrm{ml}$ of $\mathrm{H}: \mathrm{EE}: \mathrm{AA}$. The eluates were collected in liquid scintillation vials and $10 \mathrm{ml}$ of scintillation fluid (ScintiSafe Econo F; Fisher, USA) were added. Radioactivity (cpm) of the samples was measured in a liquid scintillation counter as a direct measure of FAME activity.

\section{Preparation of FAME-free concentrated culture filtrate (activator)}

Five $\mathrm{ml}$ of an overnight culture of $S$. epidermidis organisms were placed in $1 \mathrm{~L}$ of Trypticase Soy Broth (TSB; Difco) in a 2-L Erlenmeyer flask and then incubated for $16 \mathrm{~h}$ at $37^{\circ} \mathrm{C}$ with shaking. The bacterial cells were pelleted by centrifugation at $14470 \mathrm{~g}$ for $20 \mathrm{~min}$ at $4^{\circ} \mathrm{C}$. Culture filtrate was obtained and FAME was removed from it by passing it through a $3000 \mathrm{~mol}$. wt cut-off filter (Mini-Ultrasette; Pall Filtron, USA). FAME was retained by the filter while activator went through the filter. The filtrate was then frozen and lyophilised. The dried activator was suspended in $100 \mathrm{ml}(10 \times$ concentrated $)$ or $50 \mathrm{ml}(20 \times$ concentrated) of sterile distilled $\mathrm{H}_{2} \mathrm{O}$ and filter sterilised with $0.2-\mu \mathrm{m}$ sterile filters.

\section{Assay for activator activity}

Organisms were incubated in TSB overnight at $37^{\circ} \mathrm{C}$. One $\mathrm{ml}$ of the 16 -h culture was pelleted by centrifugation $(12000 \mathrm{~g})$ and suspended in sterile TSB. The cells were pelleted again and suspended as above. This procedure was repeated twice, giving a total of three washes. The washed cells were then placed in TSB to yield an $\mathrm{OD}_{600}$ of $0.05 \mathrm{SEM} 0.005$. Activator $(0.5 \mathrm{ml}$ of $10 \times$ concentrated) or TSB $(0.5 \mathrm{ml})$ was added to $4.5 \mathrm{ml}$ of washed cells. The cultures were then incubated in a roller at $37^{\circ} \mathrm{C}$ until an $\mathrm{OD}_{600}$ of 0.6 (strain 54) or 1.5 (strains $37,45,52$ ) was reached. A sample was then removed, culture filtrates were obtained and assayed for FAME activity as indicated above.

\section{Assay for exopolysaccharide}

These assays were performed as described previously [20] with the following modifications of the assay. $S$. epidermidis strain 54 was incubated in TSB for $16 \mathrm{~h}$ at $37^{\circ} \mathrm{C}$. The cells were washed in TSB as described above and then placed in TSB to yield an $\mathrm{OD}_{600}$ of $c$. 0.05 SEM 0.005. The cells $(9.5 \mathrm{ml})$ were placed in $15-\mathrm{ml}$ disposable sterile polypropylene centrifuge tubes (FisherBrand; Fisher Scientific, USA) with either $0.5 \mathrm{ml}$ of TSB or $0.5 \mathrm{ml}$ of activator $(20 \times$ concentrated $)$. Both samples were then incubated at $37^{\circ} \mathrm{C}$ in a roller and culture filtrates were obtained with various $\mathrm{OD}_{600}$ values $(0.6,1.0,1.5$, overnight cultures). The cells were then pelleted by centrifugation and assayed for exopolysaccharide as described previously [20]. Briefly, bacteria $(10 \mathrm{ml})$ were pelleted by centrifugation $(1000 \mathrm{~g}, 15 \mathrm{~min})$ and then suspended in sterile saline $(1 \mathrm{ml})$. The samples were sonicated $(2 \mathrm{~min} ; 60 \mathrm{~W}$ power). The samples were then centrifuged at $1000 \mathrm{~g}$ for $10 \mathrm{~min}$ and the supernates containing the exopolysaccharide were added dropwise to ethanol $95 \%(10 \mathrm{ml}$ at $4^{\circ} \mathrm{C}$ ). The exopolysaccharides were allowed to precipitate overnight at $-75^{\circ} \mathrm{C}$ and then collected by centrifugation $\left(10000 \mathrm{~g}, 20 \mathrm{~min}, 4^{\circ} \mathrm{C}\right)$. The pellet was suspended in $1 \mathrm{ml}$ of sterile distilled $\mathrm{H}_{2} \mathrm{O}$ mixed with $\mathrm{H}_{2} \mathrm{SO}_{4}(77 \%, 7 \mathrm{ml})$ and placed on ice for $10 \mathrm{~min}$. Tryptophan $\left(1 \% \mathrm{w} / \mathrm{v} ; 1 \mathrm{ml}\right.$ at $\left.4^{\circ} \mathrm{C}\right)$ was added and the tubes were heated in a boiling bath for $20 \mathrm{~min}$. The amount of exopolysaccharide was then measured at $\mathrm{A}_{500}$ after the samples had cooled.

\section{Characterisation of activator}

Activator was subjected to ultrafiltration to determine the approximate mol.wt of the activator (Macrosep, Pall Filtron; 10000 and 3000 mol.-wt cut-off filters). The filtrates were then assayed for activator activity as described above. Activator was boiled for $10 \mathrm{~min}$ before assaying for activator activity to determine its heat stability. Activator $(0.5 \mathrm{ml})$ was also treated with $4 \mathrm{mg}$ of proteinase K (Sigma, USA; 15 units $/ \mathrm{mg}$ ) for $2 \mathrm{~h}$ at $37^{\circ} \mathrm{C}$. Proteinase $\mathrm{K}$ was inactivated by boiling for 
$10 \mathrm{~min}$ and then assayed for activator activity as described above.

\section{Effect of activator on FAME expression at various times in the growth cycle}

Activator $(0.5 \mathrm{ml} ; 10 \times$ concentrated $)$ or TSB $(0.5 \mathrm{ml})$ was added to $4.5 \mathrm{ml}$ of washed $S$. epidermidis strain 54 cells as above, incubated at $37^{\circ} \mathrm{C}$, and at various $\mathrm{OD}_{600}$ values $(0.05,0.2,0.4,0.6,0.8$ and 1.0$)$ sample was removed, culture filtrates were obtained and assayed for FAME activity. This experiment was repeated three times. The mean and SEM values were calculated.

\section{Effect of various concentrations of activator on FAME expression}

Various volumes of $20 \times$ concentrated activator $(0,50$ $100,150,200,250$ or $300 \mu \mathrm{l})$ were added to $4.5 \mathrm{ml}$ of washed $S$. epidermidis strain 54 cells. Enough sterile TSB was added to yield a final volume of $5 \mathrm{ml}$ (starting $\mathrm{OD}_{600}$ before addition of TSB and activator was 0.05 ). Cells were then incubated at $37^{\circ} \mathrm{C}$ until the $\mathrm{OD}_{600}=0.6$. Culture filtrates were then obtained and assayed for FAME activity. This experiment was repeated four times. The mean and SEM values were calculated.

Effect of $S$. aureus activator on FAME expression by $S$. epidermidis strain 54 and of $S$. epidermidis strain 54 activator on FAME expression by $S$. aureus

Activator from both species of staphylococci was partially purified as described above and suspended to yield $20 \times$ concentrated solutions of activator. Activator $(1 \times$ final concentration) from $S$. aureus or sterile TSB was added to washed $S$. epidermidis cells (initial $\mathrm{OD}_{600}=0.05$ ). Activator from $S$. epidermidis strain 54 or sterile TSB was added to washed $S$. aureus cells (initial $\mathrm{OD}_{600}=0.05$ ). All cultures were incubated at $37^{\circ} \mathrm{C}$ until an $\mathrm{OD}_{600}$ of 0.6 was reached. Culture filtrates were obtained and assayed for FAME activity. Bacterial cells with their own respective activator and with TSB added served as controls. These experiments were repeated four times. The mean and SEM values were recorded.

\section{Activator competition experiments}

The study aimed to determine whether activator from $S$. epidermidis strain 54 inhibited expression of FAME by $S$. aureus and vice versa. Before addition of a particular species' own activator the other species' activator was added and incubated with the bacterial cells for $10 \mathrm{~min}$ at $37^{\circ} \mathrm{C}$. Bacterial cells were also incubated as above with sterile TSB, their own, or the other species' activator. The cultures were incubated as above until an $\mathrm{OD}_{600}$ of 0.6 was reached and assayed for FAME activity as described above.

\section{Statistical analysis}

Statistically significant differences in mean values were determined by the Student's $t$ test. Statistically significant differences in the means had $\mathrm{p}$ values $<0.05$.

\section{Results}

Identifying activator and optimising the activator assay

FAME was used as an indirect marker of the induction of extracellular protein expression to identify an $S$. epidermidis activator. The addition of activator to $S$. epidermidis cells resulted in a 2-5-fold increase in FAME activity (Fig. 1). The growth rates of the control samples and those with added activator were almost identical.

The initial concentration of the bacterial cells affected FAME expression. Little difference in FAME expression could be seen when samples containing activator were compared to controls if the initial $\mathrm{OD}_{600}$ was $>0.1$ (Fig. 2). The optimal starting $\mathrm{OD}_{600}$ for inducing FAME expression was $c$. 0.05 SEM 0.01. When lower optical densities were used $\left(\mathrm{OD}_{600}=0.03\right)$ the lag time increased by $2 \mathrm{~h}$, making the assay more timeconsuming. Starting samples at an $\mathrm{OD}_{600}$ of 0.05 resulted in a lag time of $c .1 \mathrm{~h}$.

Washing the cells at the beginning of the experiment resulted in lower amounts of FAME being produced by the control samples. Washed control samples had a mean FAME activity of 2513 (SD 114). Unwashed control samples had a mean FAME activity of 3177 (SD 181). If activator was added to washed and unwashed cells no significant difference was seen in FAME activity.

The $\mathrm{pH}$ of the activator, normally at a $\mathrm{pH}$ of 6.8 , did not affect the induction of FAME expression. If the $\mathrm{pH}$ of the activator was brought to neutrality with $1 \mathrm{M}$ $\mathrm{NaOH}$ the induction of FAME expression was not affected (data not shown).

The optimal $\mathrm{OD}_{600}$ values to obtain culture filtrates from $S$. epidermidis strain 54 for FAME assays were between 0.6 and 1.0 (Fig. 3; p value $<0.05$ ). Optical densities $<0.6$ did not yield statistically significant differences between controls and samples with added activator.

\section{Characterisation of $S$. epidermidis activator}

The activator was able to pass through 10000 and 3000 mol.-wt cut-off filters. Assays for activator activity of the filtrate resulted in little or no loss of activator activity even with 3000 mol.-wt cut-off filters.

If activator was boiled before it was added to the bacterial cells, induction of FAME activity was less 


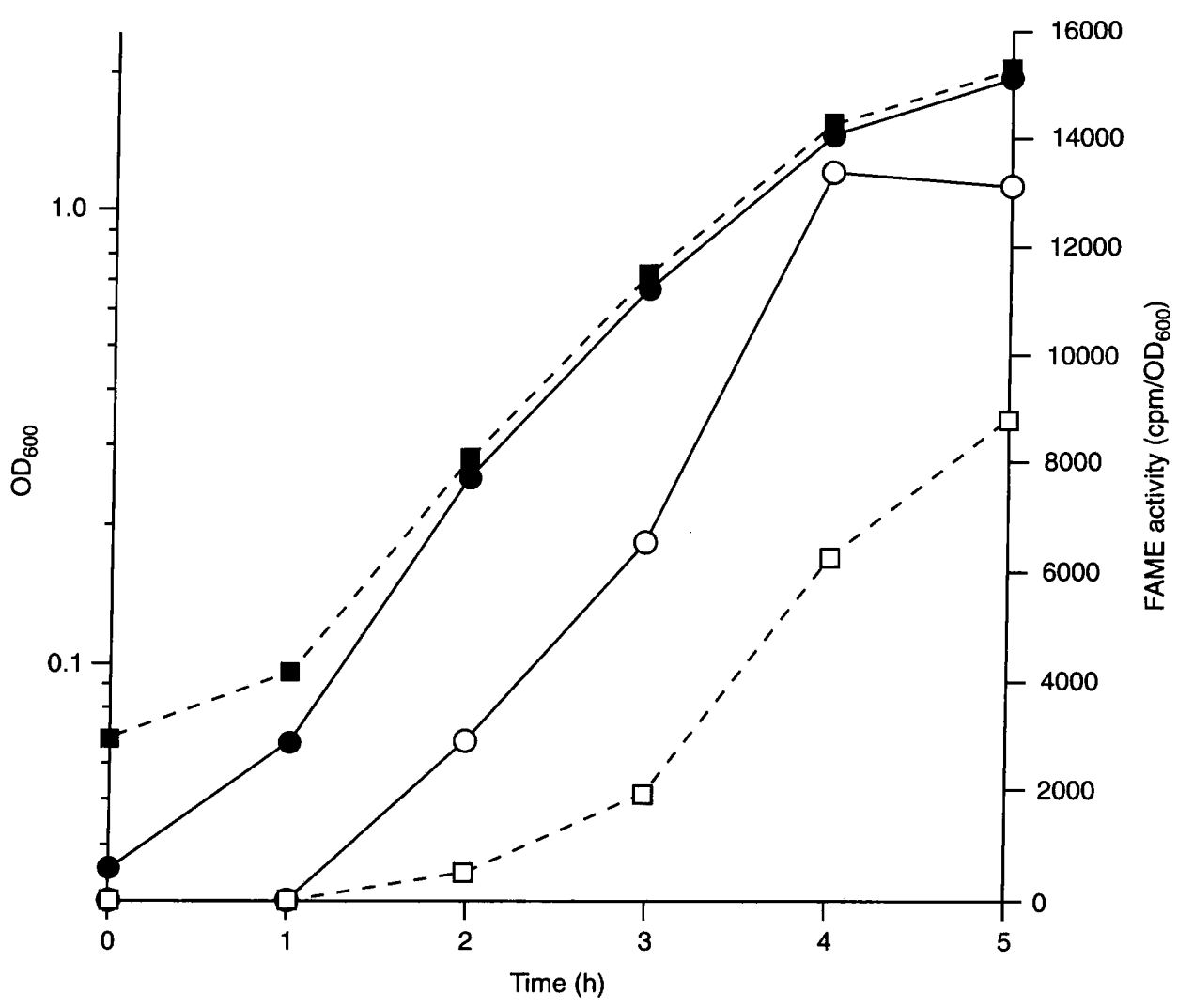

Fig. 1. Expression of FAME with and without $S$. epidermidis strain 54 activator. $O$ FAME activity $\left(\mathrm{cpm} / \mathrm{OD}_{600}\right)$ of sample, activator added; $\square$ FAME activity $\left(\mathrm{cpm} / \mathrm{OD}_{600}\right)$ of sample, no activator; $\bullet \mathrm{OD}_{600}$ of culture, activator added; - $\mathrm{OD}_{600}$ of culture, no activator.

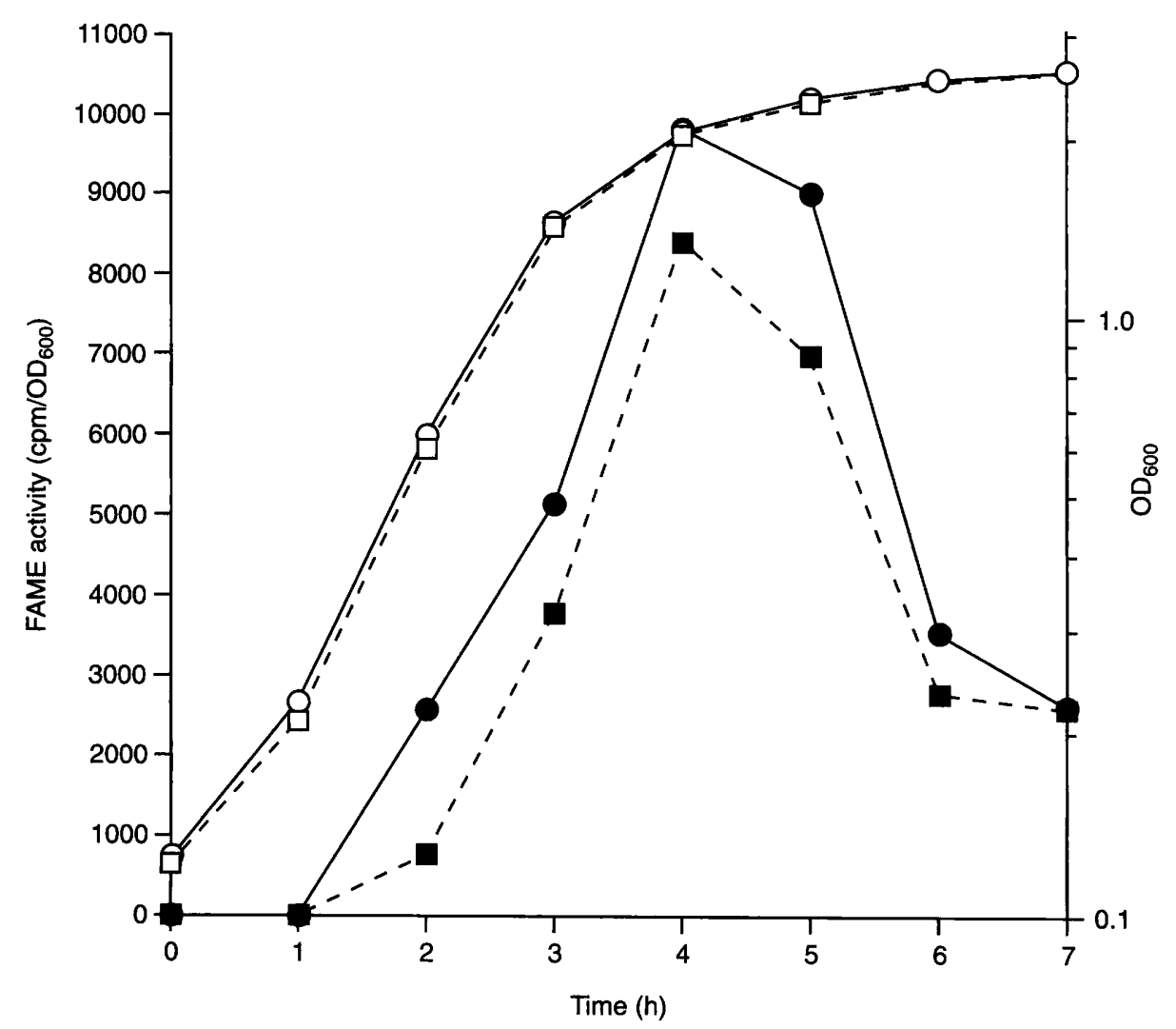

Fig. 2. Effect of higher optical density (0.1) on induction of FAME expression by $S$. epidermidis strain 54 activator. - FAME activity $\left(\mathrm{cpm} / \mathrm{OD}_{600}\right)$ of sample, activator added; FAME activity (cpm/OD $/ \mathrm{OD}_{600}$ ) of sample, no activator; $\circ \mathrm{OD}_{600}$ of culture, activator added; $\square \mathrm{OD}_{600}$ of culture, no activator. 


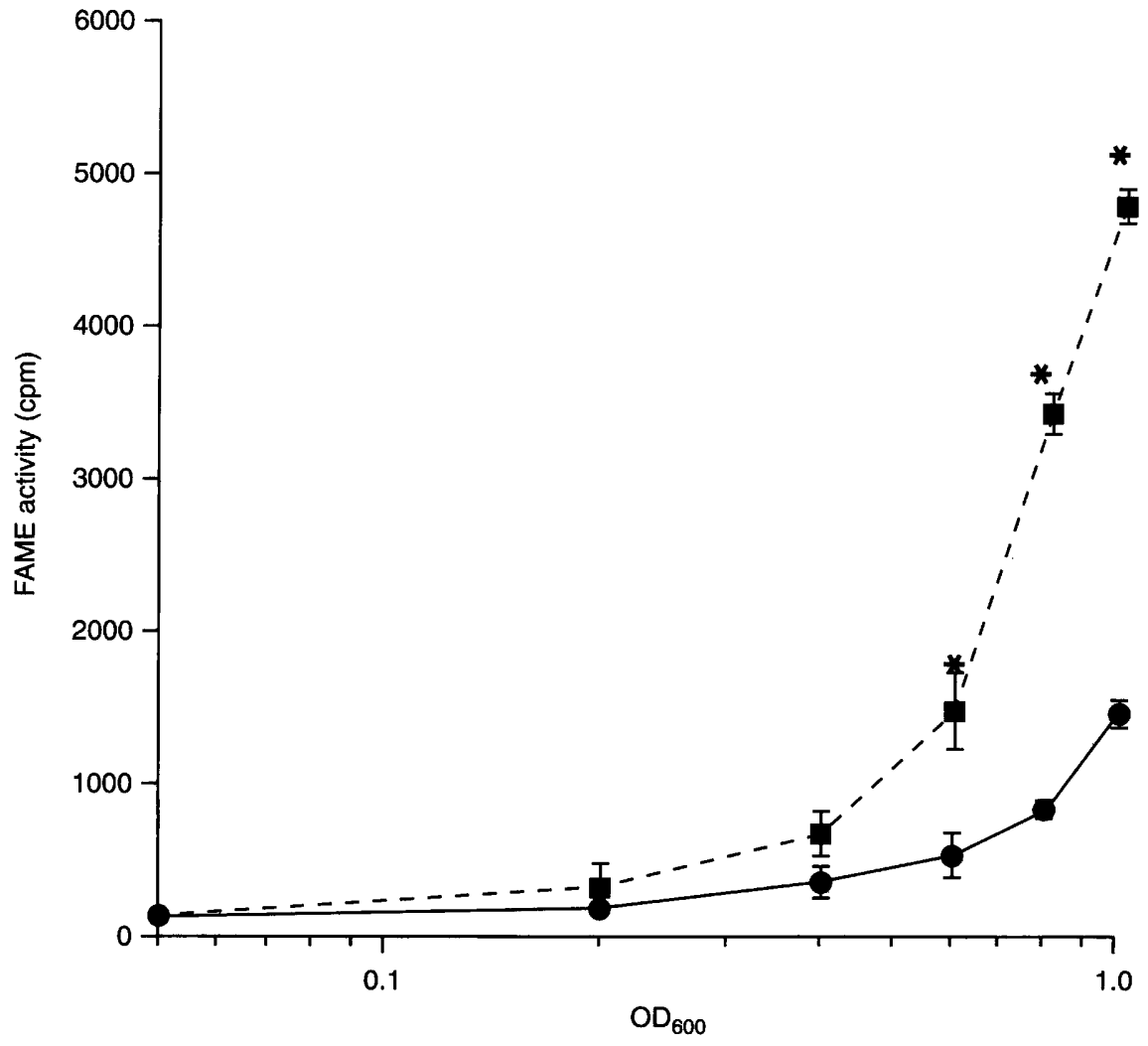

Fig. 3. Effect of $S$. epidermidis strain 54 activator on FAME production. mean FAME activity of samples, activator added; $\bullet$ mean FAME activity $\left(\mathrm{cpm} / \mathrm{OD}_{600}\right)$ of samples, no activator. FAME assays were performed in triplicate; bars, SEM. ${ }^{*}$ Differences in mean are statistically significant $(\mathrm{p}<0.05$; Student's $t$ test $)$.

(20\% less). Proteinase $\mathrm{K}$ digestion did not inactivate activator (data not shown).

A linear increase in FAME activity was observed when increasing amounts of activator were added to $S$. epidermidis. When $>100 \mu \mathrm{l}$ of $20 \times$ activator were added to the staphylococcal cells there was no significantly greater expression of FAME activity (final activator concentration $=0.41 \times$; Fig. 4). This concentration of activator was $60 \%$ less than that found in culture filtrates obtained from a 16-h culture of $S$. epidermidis.

Activator from three other $S$. epidermidis isolates (strains 37,45 and 52 ) was partially purified as above. In all three cases addition of activator to its own respective bacterial cells resulted in an increase in FAME production when the cells reached an $\mathrm{OD}_{600}$ of 1.5 (data not shown).

\section{Effect of activator on exopolysaccharide production by $S$. epidermidis}

The addition of activator did not increase the amount of exopolysaccharide at $\mathrm{OD}_{600}$ values of $0.6,1.0$ and 1.5 ; nor did it increase production of exopolysaccharide after incubation for $12 \mathrm{~h}$.

\section{Activator assay with $S$. aureus cells}

Partially purified $S$. aureus activator was placed with $S$. aureus cells to ensure that this indirect activator assay would measure increases in FAME expression. Addition of activator resulted in a 2-5-fold increase in FAME production over control samples when culture filtrates were harvested at an $\mathrm{OD}_{600}$ of 0.6 (data not shown).

\section{Activator cross-influence between $S$. aureus and $S$.} epidermidis

The addition of $S$. epidermidis activator to $S$. aureus cells did not result in any significant increase in FAME activity over controls. However, the addition of $S$. aureus activator to $S$. epidermidis cells significantly increased FAME activity over controls (Table 1; $\mathrm{p}<0.05)$.

Addition of $S$. epidermidis activator $10 \mathrm{~min}$ before the addition of $S$. aureus activator did not inhibit production of FAME by $S$. aureus. Addition of $S$. aureus activator $10 \mathrm{~min}$ before the addition of $S$. epidermidis activator also did not inhibit production of FAME by $S$. epidermidis. 


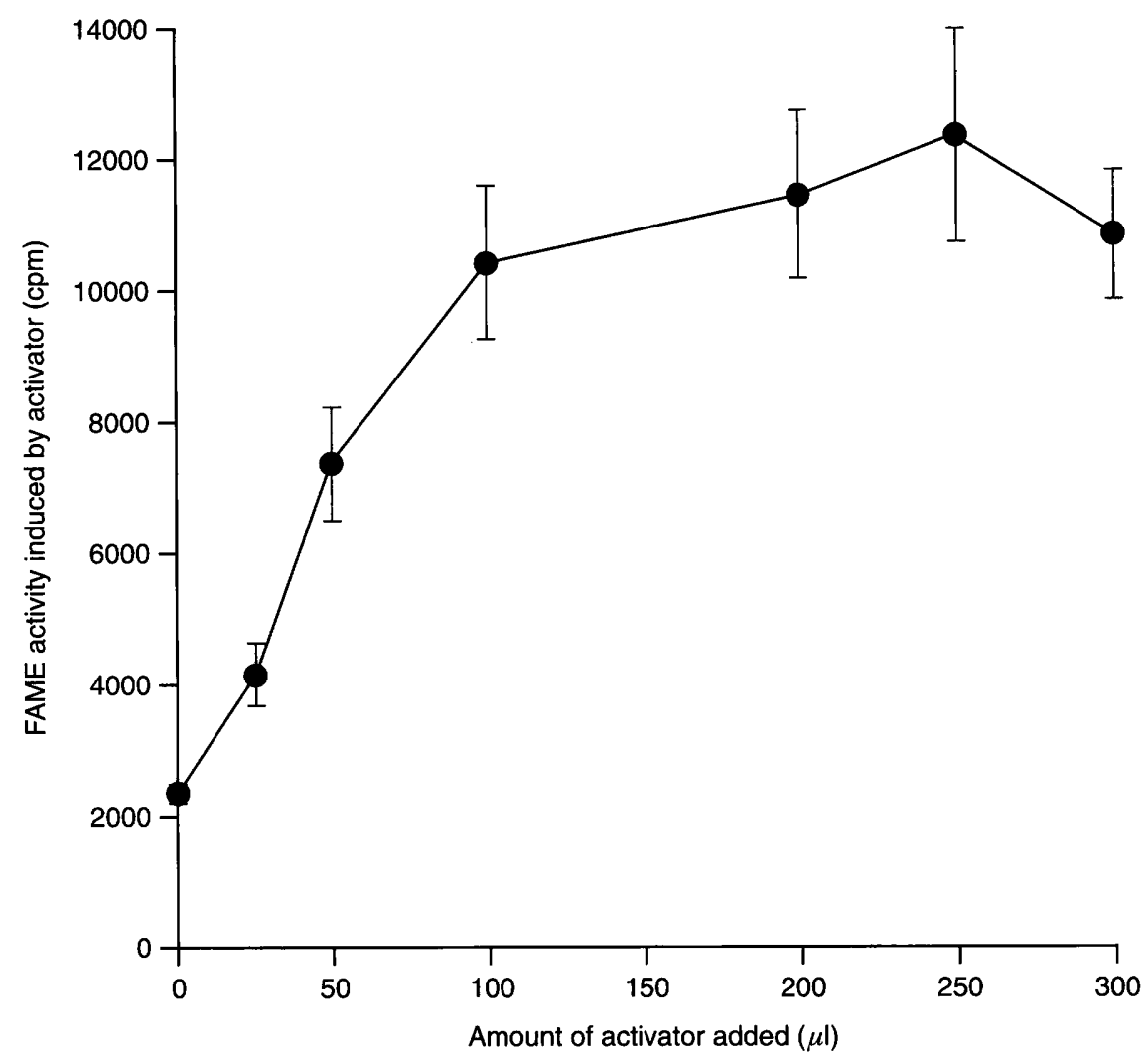

Fig. 4. Effect of increasing $S$. epidermidis strain 54 activator concentration on FAME expression. FAME activity obtained from cells at an $\mathrm{OD}_{600}$ of 0.6 minus control FAME values. Results are the average of three experiments; bars, SEM.

Table 1. Induction of FAME expression by activators from $S$. aureus and $S$. epidermidis strain 54

\begin{tabular}{llccc}
\hline Organism & Source of activator & FAME activity* & SEM & Fold increase in FAME activity (p value) \\
\hline S. aureus & None & 962 & 80 & $\ldots$ \\
S. aureus & S. aureus & 5247 & 436 & $5.45(0.0006)$ \\
S. aureus & S. epidermidis & 1176 & 83 & 1.22 (NS) \\
S. epidermidis & None & 1627 & 535 & $\ldots$ \\
S. epidermidis & S. aureus & 4657 & 437 & $2.86(0.0118)$ \\
S. epidermidis & S. epidermidis & 3952 & 168 & $2.42(0.0143)$ \\
\hline
\end{tabular}

NS, not statistically significant.

*FAME activity is expressed as the cpm of cholesterol ester produced at an $\mathrm{OD}_{600}$ of 0.6 .

${ }^{\dagger} p$ values from Student's $t$ test in comparing the means from controls with samples containing various activators; results were from four different experiments.

\section{Discussion}

This study resulted in the development of an assay for activation of FAME production by $S$. epidermidis and $S$. aureus, and also identified and partially characterised an activator of FAME production by $S$. epidermidis.

Previous studies have shown that FAME is not produced by $S$. aureus [21] and S. epidermidis [9] until early in the stationary phase of growth. This delay in FAME production by $S$. aureus is due to regulation by the agr locus [21]. The production of an activator of the agr locus has been described previously $[17,18]$. Other investigators used Northern blots to assay for activator activity $[17,18]$; Northern blotting is time-consuming and costly.

Experiments with partially purified activator from $S$. aureus resulted in the development of an inexpensive activator assay that used FAME activity as an indirect marker for $a g r$ locus induction (Table 1). Addition of activator from $S$. aureus to $S$. aureus cells resulted in a 2-5-fold increase in FAME activity compared with controls (Table 1).

An agr-like locus has also been described in $S$. epidermidis [16]. The pattern of FAME production by $S$. epidermidis is similar to agr-regulated FAME production seen in $S$. aureus [9]. An activator of $S$. epidermidis agr-like locus was sought with FAME as an indirect marker. A small $(<3 \mathrm{kDa})$, proteinase $\mathrm{K}$ resistant and heat-stable $S$. epidermidis activator of FAME production was identified by this indirect activator assay. Three other $S$. epidermidis isolates also produced an activator that increased their production of FAME. 
Attention to certain details was important to obtain optimal differences between control samples and those with added activator in this assay. Washing $S$. epidermidis cells lowered FAME production by controls; this resulted in greater differences in FAME activity between controls and samples with added activator. Washing the cells probably removed some if not all of the activator present on cells from the overnight culture. If the activator is not removed then controls could be partially activated and larger amounts of FAME would be produced by the time the culture filtrates were harvested.

The concentration of cells used initially was also important. If too few cells were used $\left(\mathrm{OD}_{600}<0.05\right)$, the lag time was prolonged (data not shown). If too many cells were used $\left(\mathrm{OD}_{600}>0.1\right)$, little or no difference in FAME activity could be seen between control and activator-added samples (data not shown). Even though the cells were washed, enough activator may still be present on the surface of the cells to cause FAME production to be induced at an earlier stage in the growth cycle. By diluting the cells at lower levels the activator present may not remain bound to the cells and thereby require the production of more activator to induce the cells to produce FAME.

The timing of culture filtrate harvest also influenced the assay. Samples taken at $\mathrm{OD}_{600}$ values between 0.6 and 1.0 yielded the largest statistically significant differences between control and samples with added activator with $S$. epidermidis strain 54 (Fig. 2). Obtaining samples too early did not appear to give the cells enough time to express detectable levels of FAME. Samples obtained at an $\mathrm{OD}_{600}>1.0$ usually resulted in more FAME being detectable in samples with added activator than in controls. However, the differences between samples with added activator and controls were less. This is probably due to the fact that extracellular proteases were more abundant at these times in the growth cycle and destroyed some of the FAME activity. A previous study has shown that a marked decrease in FAME activity observed late in the stationary phase is probably caused by extracellular proteases [9].

The strain of $S$. epidermidis used can also affect the detection of differences between samples with added activator and control samples. The optimal $\mathrm{OD}_{600}$ to sample $S$. epidermidis strain 54 was $0.6-1.0$; however, $S$. epidermidis strains 37,45 and 52 did not show significant differences in FAME production between controls and samples with added activator until an $\mathrm{OD}_{600}$ of 1.5. These strain to strain differences have also been noted in work with $S$. aureus activators [18].

Addition of $S$. epidermidis activator did not dramatically affect the growth rate of the cultures (Fig. 1). The difference in FAME activity between the samples with added activator and control samples was not caused by a difference in growth rates between the two cultures. The $\mathrm{pH}$ of the activator did not affect the ability of the $S$. epidermidis cells to produce FAME. If the $\mathrm{pH}$ of the activator was brought to 7.0 before adding it to washed $S$. epidermidis cells, the sample containing activator still produced more FAME than did the controls.

Addition of activator did not increase exopolysaccharide production by $S$. epidermidis. Other investigators have shown that the amount of exopolysaccharide produced by $S$. epidermidis is inversely proportional to the growth rate of a sessile culture [20]. Planktonic cultures do not produce as much exopolysaccharide as sessile cultures. The addition of activator by itself is not the reason sessile cultures produce more exopolysaccharide.

Increasing the amount of activator added to a constant number of $S$. epidermidis cells resulted in increased levels of FAME being produced. The amount of FAME activity expressed by the cells increased at a linear rate until $\geqslant 100 \mu \mathrm{l}$ of activator was added. The rate of increase in FAME production was much less when $>100 \mu \mathrm{l}$ of the activator was added. This indicates that the receptors for the activator were probably saturated and the cells could not bind any more activator. Also, the cells appear to bind to the activator in a specific manner. Non-specific interactions of extracellular factors with the cell surface usually require very high levels of the extracellular factor before saturation is achieved.

Three different $S$. aureus strain-specific activators have been identified to date [18]. These activators were from seven to nine peptides in length. The DNA sequences of these activators were divergent and addition of an activator from one strain of $S$. aureus neither inhibited nor activated the agr locus of a different strain of $S$. aureus [18]. The study also demonstrated that activator from $S$. lugdunensis inhibited the induction of the $S$. aureus agr locus in all the $S$. aureus strains tested [18].

The present study demonstrated that activator from $S$. epidermidis strain 54 did not induce $S$. aureus cells to produce FAME (Table 1). However, $S$. aureus activator was able to induce FAME production by $S$. epidermidis strain 54 (Table 1). Neither of the activators was able to inhibit the ability of the other species to produce FAME.

It appears from these studies that an activator of gene expression also exists in $S$. epidermidis. The activator from $S$. epidermidis is different to that of $S$. aureus in that it is less heat resistant, resistant to proteinase $\mathrm{K}$ treatment and is unable to activate $S$. aureus cells to produce FAME. The $S$. epidermidis activator does not induce the expression of exopolysaccharide by $S$. epidermidis cells. 
The exact mechanisms of activator gene induction were not determined. However, it is highly likely that the $S$. epidermidis activator is involved in binding to an Agr-like receptor protein that then eventually activates or inhibits gene expression, as has been demonstrated in $S$. aureus $[17,18]$.

Previous studies have demonstrated that FAME [9] and lipase [12] are not detectable in culture filtrates of $S$. epidermidis until early stationary phase. This pattern of protein expression is similar to agr-regulated FAME production in $S$. aureus [21]. Induction of agrregulated proteins initially involves the binding of an extracellular activator to a surface receptor $[17,18]$.

This ability to delay production of extracellular factors may be beneficial to $S$. epidermidis. When organisms are few in number very few nutrients are needed. However, as organism numbers increase other and more diverse sources of nutrients are needed. Lipase can break down triglycerides from sebaceous gland secretions to glycerol and fatty acids. The fatty acids obtained from breakdown of triglycerides could be utilised by the bacteria. Unfortunately, if the fatty acid concentration gets too high it can kill the staphylococci. The ability of FAME to inactivate some of these fatty acids by esterification of the fatty acids to cholesterol may help to lower fatty acid concentrations and possibly protect the organisms from killing themselves in search of other sources of nutrients. Delaying expression of lipase and FAME until later in the growth cycle would conserve energy and the coordinated expression of these two factors may help the organisms survive for longer periods of time on the skin.

Future studies will involve purification and further characterisation of the activator(s) from $S$. epidermidis. Other studies will be conducted to determine what, if any, other factors are affected by addition of this activator and the exact mechanisms for FAME expression will also be determined.

I thank Betty Cox, Julie Blessing and Kimberly Williams for excellent technical support during this project. These studies were supported in part by Public Health Service grant R15AI-3119 from the National Institute of Allergy and Infectious Diseases to N.R.C.

\section{References}

1. Foster TJ. Chapter 12. Staphylococcus. In: Baron S (ed) Medical microbiology, 4th edn. Galveston, TX, University of Texas Medical Branch at Galveston. 1996: 187-197.
2. Goldmann DA, Pier GB. Pathogenesis of infections related to intravascular cathererization. Clin Microbiol Rev 1993; 6: $176-192$.

3. Christensen GC. The 'Sticky' problem of Staphylococcus epidermidis sepsis. Hosp Pract 1993; 27-38.

4. Kanai K, Kondo E. Antibactericidal and cytotoxic aspect of long-chain fatty acids as cell surface events: selected topics. Jpn J Med Sci Biol 1979; 32: 135-174.

5. Shryock TR, Dye ES, Kapral FA. The accumulation of bactericidal lipids in staphylococcal abscesses. J Med Microbiol 1992; 36: 332-336.

6. Shryock TR, Kapral FA. The production of bactericidal fatty acids from glycerides in staphylococcal abscesses. $J$ Med Microbiol 1992; 36: 288-292.

7. Engler HD, Kapral FA. The production of a bactericidal monoglyceride in staphylococcal abscesses. $J$ Med Microbiol 1992; 37: 238-244.

8. Long JP, Hart J, Albers W, Kapral FA. The production of fatty acid modifying enzyme (FAME) and lipase by various staphylococcal species. J Med Microbiol 1992; 37: 232-234.

9. Chamberlain NR, Brueggemann SA. Characterisation and expression of fatty acid modifying enzyme produced by Staphylococcus epidermidis. $J$ Med Microbiol 1997; 46: 693-697.

10. Mortensen JE, Shryock TR, Kapral FA. Modification of bactericidal fatty acids by an enzyme of Staphylococcus aureus. J Med Microbiol 1992; 36: 293-298.

11. Kapral FA, Smith S, Lal D. The esterification of fatty acids by Staphylococcus aureus fatty acid modifying enzyme (FAME) and its inhibition by glycerides. J Med Microbiol 1992; 37: 235-237.

12. Farrell AM, Foster TJ, Holland KT. Molecular analysis and expression of the lipase of Staphylococcus epidermidis. J Gen Microbiol 1993; 139: 267-277.

13. Kornblum J, Kreiswirth BN, Projan SJ, Ross H, Novick RP. Agr: a polycistronic locus regulating exoprotein synthesis in Staphylococcus aureus. In: Novick RP (ed) Molecular biology of the staphylococci. New York, VCH Publishers. 1990: 373-402.

14. Novick RP, Ross HF, Projan SJ, Kornblum J, Kreiswirth B, Moghazeh S. Synthesis of staphylococcal virulence factors is controlled by a regulatory RNA molecule. EMBO $J$ 1993; 12: 3967-3975.

15. Balaban N, Novick RP. Translation of RNAIII, the Staphylococcus aureus agr regulatory RNA molecule, can be activated by a 3'-end deletion. FEMS Microbiol Lett 1995; 133: $155-161$.

16. Willem JB, Wamel V, Verhoef J, Fluit ADC. Cloning and characterization of an accessory gene regulator (agr)-locus in Staphylococcus epidermidis. In: 96th General Meeting of the American Society for Microbiology. Washington, DC, American Society for Microbiology. 1996: B-338, p. 213.

17. Balaban N, Novick RP. Autocrine regulation of toxin synthesis by Staphylococcus aureus. Proc Natl Acad Sci USA. 1995: 92: 1619-1623.

18. Ji G, Beavis R, Novick RP. Bacterial interference caused by autoinducing peptide variants. 1997. Science. 276: 2027-2030.

19. Patel $\mathrm{AH}$, Nowlan $\mathrm{P}$, Weavers $\mathrm{ED}$, Foster $\mathrm{T}$. Virulence of protein A-deficient and alpha-toxin-deficient mutants of Staphylococcus aureus isolated by allele replacement. Infect Immun 1987; 55: 3103-3110.

20. Evans E, Brown MRW, Gilbert P. Iron chelator, exopolysaccharide and protease production in Staphylococcus epidermidis: a comparative study of the effects of specific growth rate in biofilm and planktonic culture. Microbiology 1994; 140: $153-157$.

21. Chamberlain NR, Imanoel B. Genetic regulation of fatty acid modifying enzyme from Staphylococcus aureus. $J$ Med Microbiol 1996; 44: 125-129. 